\title{
GABA-induced Chemokinesis and NGF-induced Chemotaxis of Embryonic Spinal Cord Neurons
}

\author{
T. N. Behar, ${ }^{1}$ A. E. Schaffner, ${ }^{\prime}$ C. A. Colton, ${ }^{2}$ R. Somogyi, ${ }^{1}$ Z. Olah, ${ }^{3}$ C. Lehel, ${ }^{3}$ and J. L. Barker ${ }^{1}$ \\ 'Laboratory of Neurophysiology, National Institute of Neurological Disorders and Stroke, National Institutes of Health, \\ Bethesda, Maryland 20892, 'Department of Physiology and Biophysics, Georgetown University Medical School, \\ Washington, DC 20007, and ${ }^{3}$ Laboratory of Cellular Oncology, National Cancer Institute, National Institutes of Health, \\ Bethesda, Maryland 20892
}

During CNS development, neuroblasts proliferate within germinal zones of the neuroepithelium, and then migrate to their final positions. Although many neurons are thought to migrate along processes of radial glial fibers, increasing evidence suggests environmental factors also influence nerve cell movement. Extracellular matrix molecules are thought to be involved in guiding neuronal migration, and molecules such as NGF and GABA exert trophic effects on immature neurons. The nature of the signals that initiate and direct neuroblast migration, however, is unknown. In vitro, NGF and GABA promote neurite outgrowth from cultured cells, and NGF induces axonal chemotaxis (directed migration along a chemical gradient). At earlier developmental stages, these molecules could influence neuroblast movement. Therefore, we investigated whether these molecules induce embryonic neuronal migration.

Using an in vitro microchemotaxis assay, we show that rat embryonic spinal cord neurons migrate toward picomolar NGF and femtomolar GABA beginning at embryonic day 13 (E13). Cells exhibit chemotactic responses to NGF while GABA stimulates chemokinesis (increased random movement). GABA effects are mimicked by muscimol and inhibited by bicuculline and picrotoxin, suggesting GABA motility signals are mediated by GABA receptor proteins. Expression of GABA receptors by embryonic cord cells has been previously reported (Mandler et al., 1990; Walton et al., 1993). We used polymerase chain reaction analysis to demonstrate the presence of NGF and trk MRNA in E13 and E14 cord cells, indicating the cells express message for both NGF and high-affinity NGF receptors. Immunohistochemistry of E13 spinal cord sections indicates that NGF and GABA colocalize in fibers close to the target destinations of migrating neurons, suggesting diffusible gradients of these molecules provide chemoattractant signals to migratory cells. Thus, in vitro, neuroblast migration is induced by specific signaling molecules that are present in the developing spinal cord, and may stimulate migration of embryonic neurons prior to synaptogenesis.

[Key words: migration, development, CNS, chemoattractant, motility, rat]

\footnotetext{
Received Feb. 3, 1993; revised May 19, 1993; accepted June 15, 1993

We thank Dr. Jibin Yao for helpful discussions in the preparation of the manuscript.

Correspondence should be addressed to T. Behar, Building 36, Room 2C02, NIH, Bethesda, MD 20892.

Copyright (C) 1994 Society for Neuroscience $0270-6474 / 94 / 140029-10 \$ 05.00 / 0$
}

During the course of CNS development, neuroblasts undergo a migratory phase. Following terminal mitosis, neurons exit the neuroepithelium and migrate toward their final destinations. Many neurons appear to move along the fibers of radial glial cells (Rakic, 1972, 1990; Hatten, 1990), which extend from the mitotic zone to the pial surface. Some neurons, however, appear to migrate on alternative pathways. Studies following the fate of clonally related neuroblasts in the developing cortex suggest that many neurons migrate along routes that are not aligned with radial glial fibers (Walsh and Cepko, 1992). Furthcrmorc, neurons in slice preparations have been observed to move orthogonally, along nonradial pathways that are perpendicular to the axis of glial processes (Markham and Vaughn, 1991; Fishell et al., 1992; O'Rourke et al., 1992). This suggests that during development, other mechanisms influence nerve cell movement. Increasing evidence indicates that directional migratory cues are provided by a combination of sources, including environmental factors.

Two studies provide evidence that within the spinal cord, neuroblast migration is influenced by environmental signals located in the ventral half of the cord. Disruption of the floor plate during early embryonic stages results in aberrant ventral horn development (Hirano et al., 1991). In addition, embryonic motoneurons transplanted into dorsal cord regions migrate back to the ventral horns, suggesting positional cues may be provided by other motoneuronal cells or the developing floor plate (Eisen, 1991). The nature of the signals that direct the migration of the transplanted motoneurons back to their appropriate positions is unknown. Since the transplants were separated from the cells of the ventral horns and floor plate, it is possible that gradients of diffusible factors, acting as chemoattractants, guided the cells back to their original locations.

Molecules that arc possiblc candidates for chemoattractants should be present in appropriate locations and be released by cells. Two molecules that meet these criteria are NGF and GABA. We find that the two molecules colocalize in fibers surrounding the floor plate and ventral horns of the embryonic cord when neuroblasts in the ventral half of the cord are migrating out of the neuroepithelium toward the ventral horns (Nornes and Das, 1974). Release of GABA and NGF from growth cones and cells has been described (Gordon-Weeks et al., 1984; Levi-Montalcini, 1987). The release of these two molecules near the target destinations of migrating neurons could provide chemotropic signals that initiate and/or direct neuroblast migration. It would therefore be valuable to determine whether GABA or NGF exerts chemotropic effects on acutely dissociated neuroblasts. 


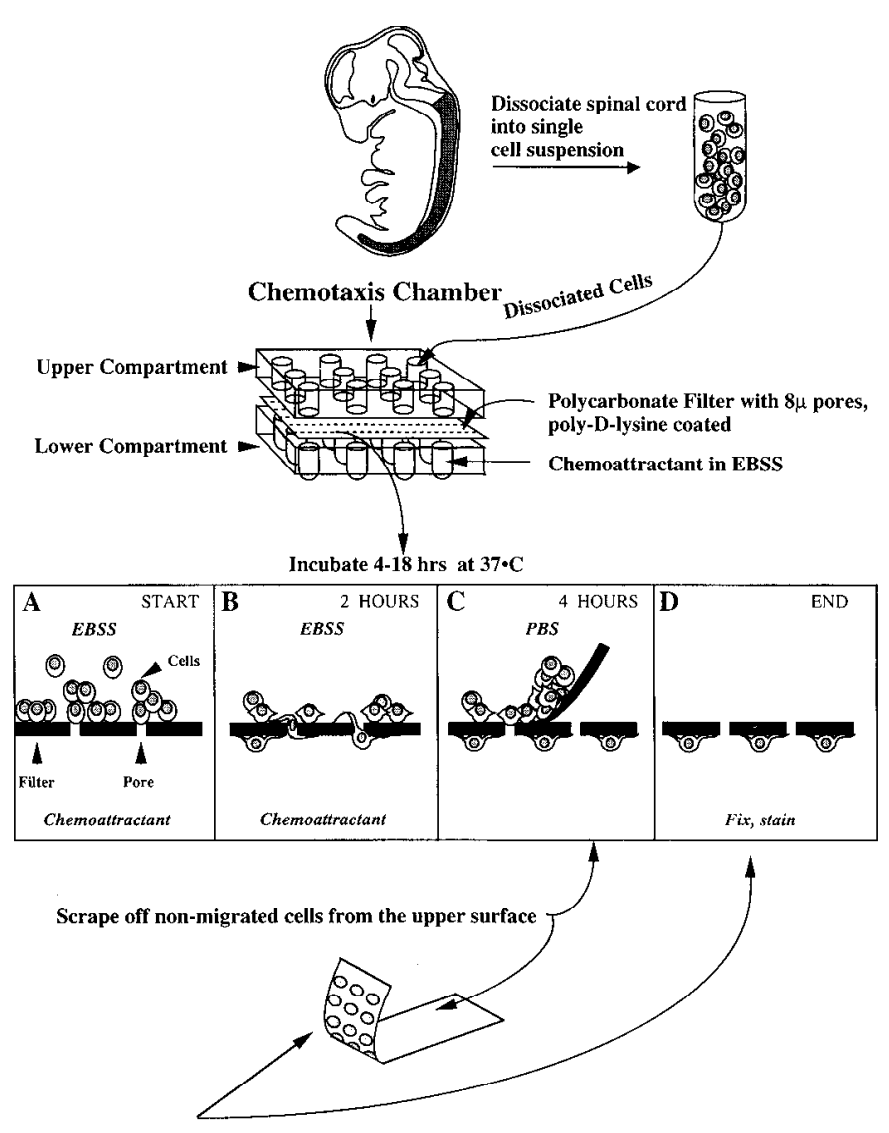

Fix, stain, and count migrated cells on the underside of the the filter

Figure 1. Schematic diagram of the microchemotaxis assay. Embryonic spinal cords are dissected and dissociated as described in Materials and Methods; $29 \mu \mathrm{l}$ of chemoattractant is placed into the round-bottom wells in the lower compartment of the microchemotaxis chamber. The chemoattractants are covered with a filter containing $8 \mu \mathrm{m}$ pores, which was precoated with poly-D-lysine. The upper compartment of the chamber is placed on top of the filter, such that the open-bottom wells of the upper compartment align with the lower wells; $5 \times 10^{1}$ cells in $50 \mu \mathrm{l}$ of EBSS are placed in each upper well, and the assembled chamber is incubated 4 or $18 \mathrm{hr}$ at $37^{\circ} \mathrm{C}$ in $5 \% \mathrm{CO}_{2}$ and $95 \%$ air. $A-D$ are enlarged insets depicting the movement of the cells through the pores of the filter. Initially, cells settle onto the filter, and some cells settle within pores $(A)$. During the incubation, cells that are stimulated to move toward the chemoattractants squeeze through the pores $(B)$. At the end of the incubation, the chamber is disassembled, and the cells on the upper side of the filter, which failed to migrate completely through the pores, are washed in PBS and scraped off $(C)$. The cells that migrated through the pores and adhered to the coated underside of the filter are fixed, stained, and counted $(D)$ as described in Materials and Methods.

Cellular chemotaxis can only be directly demonstrated in vitro. Using the microchemotaxis assay developed by Falk et al. (1980), the chemotropic responses of cells can be readily analyzed. This assay has been used to quantitate the chemotropic responses of several migratory cell types including neutrophils (Harvath et al., 1980), microglial cells (Yao et al., 1990), and O-2A progenitors (Armstrong et al., 1990). In this assay acutcly dissociated cells, suspended in buffer, are placed in the upper half of the chemotaxis chamber. Soluble chemoattractants are placed in the bottom half of the chamber, and cells are separated from the chemoattractants by a filter containing $8 \mu \mathrm{m}$ pores. Cells induced to migrate squeeze through the pores, and then adhere to the underside of the filter, which is precoated with polylysine to promote adhesion. Migrated cells that adhere to the underside of the filter are then fixed and counted.

In the present study, we provide evidence that both NGF and GABA stimulate the migration of neuronal cell bodies isolated from embryonic rat spinal cords. A scenario in which the chemoattractant effects of these two factors may be coordinated to direct the migration of newly generated neurons is discussed.

\section{Materials and Methods}

Preparation of cells. Spinal cords from pregnant Sprague-Dawley rat pups at embryonic days 12 (E12), E13, E14, and E15 were analyzed. Embryonic age was determined by appearance of a vaginal plug (day 1) and measurement of crown-rump length (Schaffner et al., 1993). Spinal cords were dissected from rat embryos, cleaned of meninges, and dissociated into single-cell suspensions by gentle papain digest under sterile conditions, as described elsewhere (Behar et al., 1993). Following dissociation, cells were resuspended in Earle's Balanced Salt Solution (EBSS) at a concentration of $10^{6}$ cells $/ \mathrm{ml}$.

Chemotaxis assay. A schematic diagram of the microchemotaxis assay is presented in Figure 1. Embryonic spinal cords were dissected and dissociated into single-cell suspensions as described above; $29 \mu \mathrm{l}$ of potential chemoattractant (NGF, GABA, muscimol, or L-leucine), diluted in EBSS, was placed into the wells of the lower compartment of a 48-well microchemotaxis chamber (Neuroprobe, Cabin John, MD). Fifty microliters of acutely dissociated cell suspension were placed in the open-bottom wells of the upper half of the chamber. The. wells in the upper half of the chamber align with the wells in the lower half, such that cells in each upper well directly oppose a well containing soluble chemoattractant. The cells were separated from the chemoattractants by a polyvinylpyrrolidone-free polycarbonate filter containing $8 \mu \mathrm{m}$ pores. Prior to assembly, the filter was treated with poly-D-lysine (20 $\mathrm{\mu g} / \mathrm{ml}$; Collaborative Rescarch, Bedford, MA) to promote adhesion.

As cells settled onto the upper surface of the membrane, some cells settled within pores, so that the lower side of the cell was exposed to the chemoattractant while its other side was exposed to buffer only. The diameter of the pores of the filter is smaller than the diameter of the cells. Thus, cells induced to migrate had to squeeze through the pores, toward the chemoattractant. As cells passed through pores, they adhered to the polylysine-coated underside of the membrane.

Cells and chemoattractants were incubated in the chemotaxis chambers for 4 or $18 \mathrm{hr}$ at $37^{\circ} \mathrm{C}$ with $5 \% \mathrm{CO}_{2}$ and $95 \%$ air. Following the migration-incubation, the chambers were disassembled. Cells on the upper surface of the filter that failed to migrate were scraped off. The cells that migrated through the pores and adhered to the underside of the membrane were then fixed, stained, and counted as described below.

Quantification of migration. In quantitative assays, cells that adhered to the underside of the membrane were fixed $30 \mathrm{~min}$ in $4 \%$ paraformaldehyde (PF) with $0.1 \%$ glutaraldehyde in $0.1 \mathrm{~m}$ phosphate buffer,

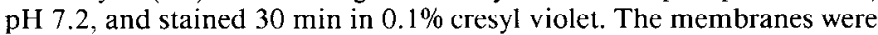
mounted cell side up onto 2 inch $\times 3$ inch glass slides, allowed to air dry, and then covered with immersion oil.

Only cells that passed completely through the pores, and migrated out onto the underside surface of the membrane were considered positive cells (Fig. $2 A$ ). In some instances, the stained cytoplasm of a cell that lay within pore but had failed to migrate completely through was evident (Fig. 2B). Cells that failed to pass completely through the pores were not included in the migrated population. Spontaneous migration of cells in control wells was observed in all assays. The average number of migrated cells in EBSS-containing wells ranged from 10 to 175 cells/ $\mathrm{mm}^{2}$. Experiments in which there was a high level of spontaneous migration resulted in greater absolute numbers of cells responding to chemoattractants.

For quantitative analysis, cells were counted using oil immersion $25 \times$ or $40 \times$ Zeiss Planapo objectives on a Leitz photomicroscope. Each chemoattractant condition was run in triplicate wells. Five to ten fields of stained cells were counted for each well, and the average number of migrated cells $/ \mathrm{mm}^{2}$ for each chemoattractant condition was calculated. Data were normalized by dividing the number of cells $/ \mathrm{mm}^{2}$ in test wells by the number of cells $/ \mathrm{mm}^{2}$ in control wells containing buffer only, and are presented as the $n$-fold increase in migrated cells relative to the number of cells migrating spontaneously. Illustrations are representative plots from individual experiments. A total of 15 migration assays were analyzed (E12, $n=3$; E13, $n=13 ; \mathrm{E} 14, n=13 ; \mathrm{E} 15, n=4)$. 

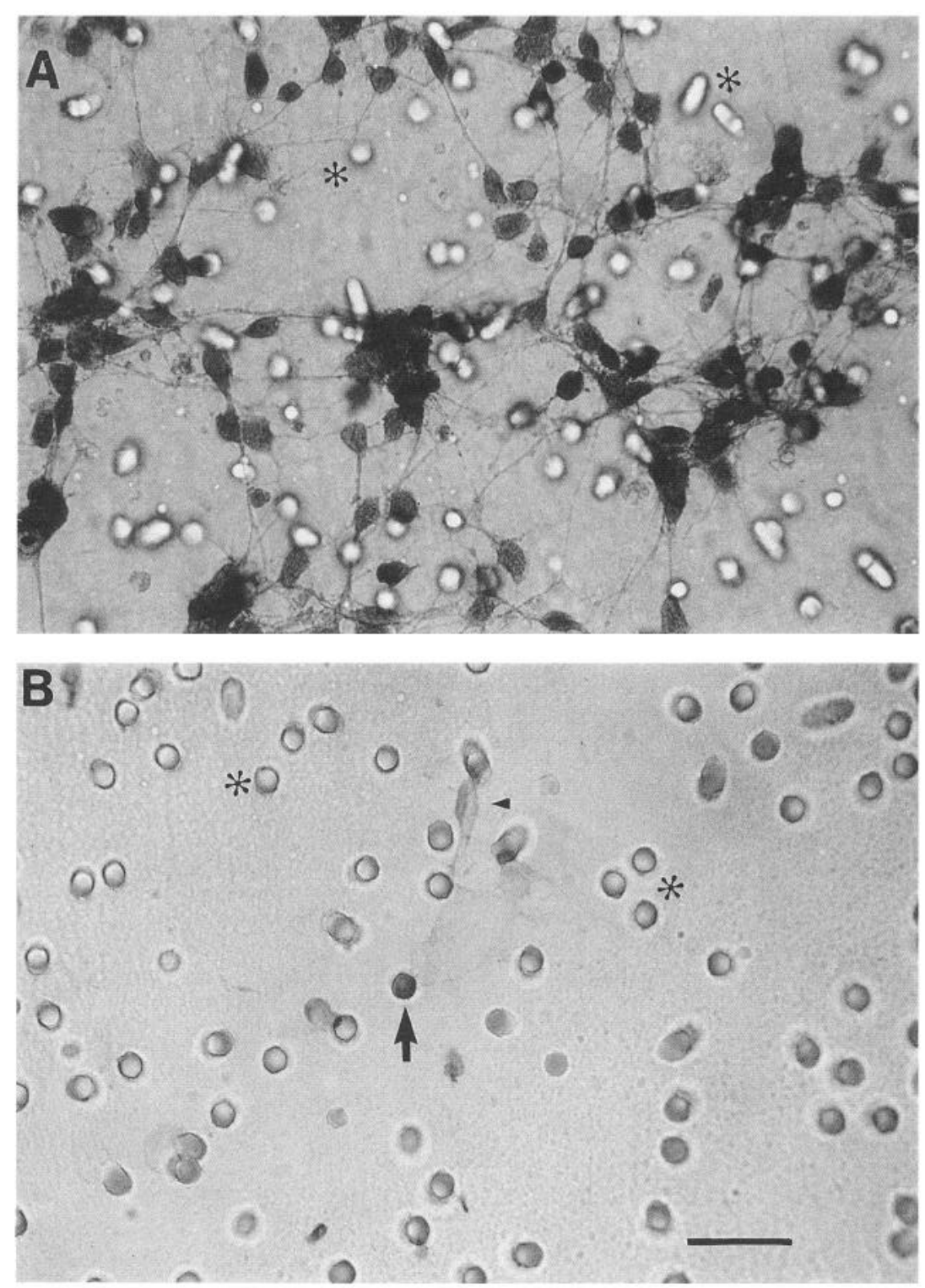

Figure 2. Photomicrographs of E14 cells that migrated to the underside of the filter. $A$, Many cells migrated in response to $1 \mathrm{ng} / \mathrm{ml} \mathrm{NGF}$. Asterisks indicate pores of the filter. $B$, In a different region of the same filter, few cells spontaneously migrated in response to buffer alone (arrowhead). Arrow indicates a pore filled with the cytoplasm of a cell that failed to migrate completely through. Scale bar, $32 \mu \mathrm{m}$.
Chemotaxis (the directed migration of cells toward regions of higher concentrations of a chemical attractant) was distinguished from chemokinesis (stimulation of increased random cell motility) by placing the same concentration of chemoattractant in both the upper and lower wells of the chamber, thereby eliminating a chemical gradient (NGF, 1 $\mathrm{ng} / \mathrm{ml}$; GABA, $5 \times 10^{-8} \mathrm{M}$; or muscimol, $\left.5 \times 10^{-10} \mathrm{M}\right)$. The number of cells migrating under these conditions was considered a measure of chemokinesis. E1 3 cells were incubated in chemotaxis chambers for 4 $\mathrm{hr}$ at $37^{\circ} \mathrm{C}$, and then fixed, stained, and counted as described previously.

Inhibition of migration. In some experiments GABA $\left(5 \times 10^{-8} \mathrm{M}\right)$ and two concentrations of NGF $\left(3.8 \times 10^{-11} \mathrm{M}\right.$, and $3.8 \times 10^{-9} \mathrm{M} ; 1$ $\mathrm{ng} / \mathrm{ml}$ or $100 \mathrm{ng} / \mathrm{ml}$, respectively) were preabsorbed for $1 \mathrm{hr}$ at room temperature with antibodies, prior to placing them into the lower wells of the microchemotaxis chamber. GABA was incubated with guinea pig anti-GABA antiserum (Eugene Tech. Inc., Allendale, NY) diluted in EBSS to $1: 50$ or $1: 100$. This antibody does not require glutaraldehyde fixation for detection of GABA by immunocytochemistry. NGF was incubated with anti-NGF antiserum $(25 \mu \mathrm{g} / \mathrm{ml}$; Boehringer Mannheim, Indianapolis, IN). Control wells for these studies consisted of placing EBSS or antibodies alone in the lower wells of the chambers.

In competition assays, muscimol $\left(5 \times 10^{-10} \mathrm{M}\right.$ final concentration) was mixed with serial dilutions of the $\mathrm{GABA}_{\mathrm{A}}$ antagonists bicuculline or picrotoxin.

Characterization of migrated cells by immunocytochemistry. In some assays, cells on the underside of the filter were characterized by im- munolabeling with anti-neurofilament antibody (anti-NF; a gift from Dr. C. Gibbs, NINDS, Bethesda, MD) at the end of the incubation period. For immunofluorescent labeling, migrated cells were fixed 30 $\min$ in $4 \% \mathrm{PF}$ with $0.1 \%$ glutaraldehyde, washed, and incubated overnight at $4^{\circ} \mathrm{C}$ in mouse anti-NF (tissue culture supernatant at $1: 8$ ). The cells were washed three times and incubated $1 \mathrm{hr}$ at $21^{\circ} \mathrm{C}$ in fluoresceinconjugated secondary antibodies (FITC-goat anti-mouse IgM, 1:40; Jackson Immunoresearch, West Grove, PA). After immunolabeling, nuclei of all cells were identified by incubating them for $5 \mathrm{~min}$ in propidium iodide ( $50 \mu \mathrm{g} / \mathrm{ml}$; Sigma, St. Louis, MO), which intercalates into double-stranded DNA and fluoresces a brilliant orange using the FITC filters. Membranes were mounted cell side up onto slides and covered with coverslips. Incubations with secondary antibodies were carried out at room temperature. Phosphate-buffered saline, $\mathrm{pH} 7.4$ (PBS), was used for all washes, and PBS with $0.25 \%$ Triton X-100 was used as the antibody diluent.

The total number of migrated cells within a field was determined by counting the number of propidium iodide-labeled nuclei. The number of immunolabeled cells was then counted in the same field, and the percentage of cells expressing NF was calculated. A total of 15 fields were counted in three replicate wells, and the average percentage of immunolabeled cells was determined. Labeled cells were examined on a Leitz photomicroscope equipped with epifluorescence and appropriate filters for the visualization of fluorescein (FITC), using $25 \times$ and $40 \times$ Zeiss Planapo objectives. In some studies, migrated cells were analyzed 

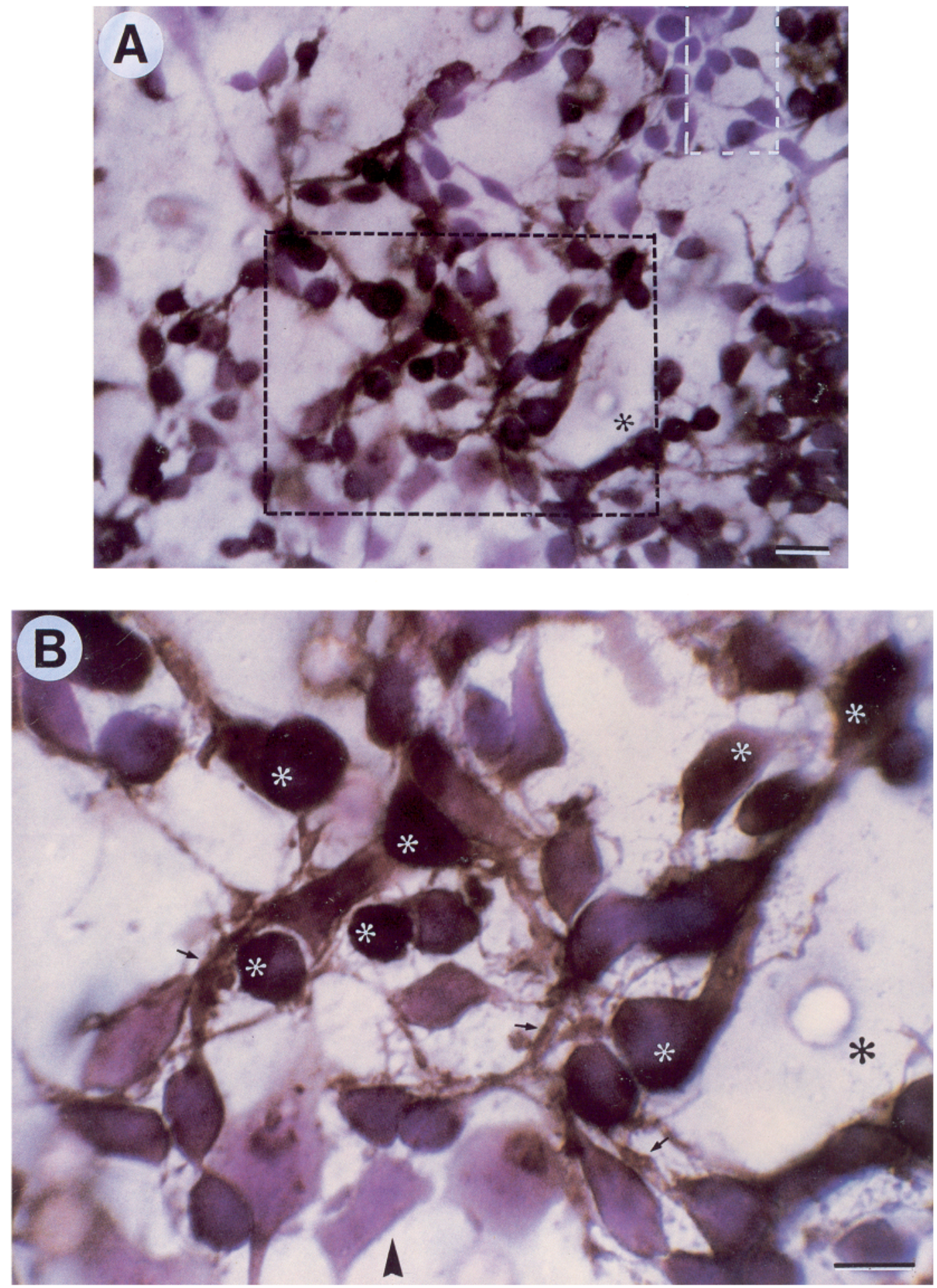

Figure 3. Photomicrographs of E14 cells that were immunoperoxidase labeled for NF and counterstained with cresyl violet following migration to femtomolar GABA. Following migration, cells were stained with cresyl violet, and then immunolabeled for NF using peroxidase-labeled antibodies as described in Materials and Methods. A, Cresyl violet staining labeled all cells that migrated in response to GABA. Anti-NF immunoperoxidase labeling, which appears as a brown immunoreaction product, revealed that most of the responding cells expressed NF. The white box $(A)$ surrounds a cluster of migrated cells that did not label with anti-NF antibodies. The black box $(A)$ delineates an area within the field that was enlarged to illustrate the double labeling of the cells. $B$, Higher magnification of the area within the black box in $A$ reveals that many cell bodies contained NF. Several NF-positive cells are indicated with white asterisks. One cell in the cluster (arrowhead) did not label with the antibodies. The small arrows indicate some of the neurites that contained immunoreaction product. The black asterisks $(A, B)$ indicate membrane pores. Scale bars: $A$, $20 \mu \mathrm{m} ; B, 12 \mu \mathrm{m}$. 
GABA

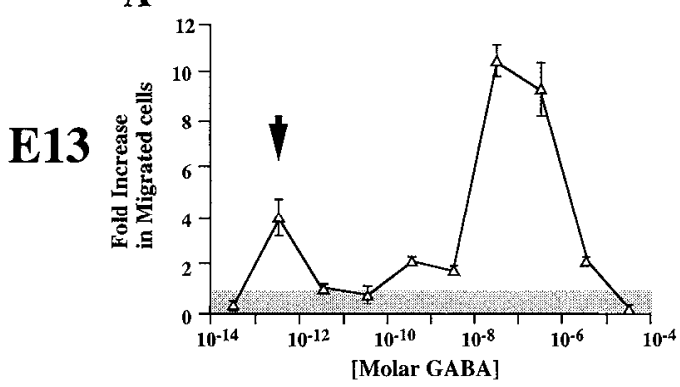

C

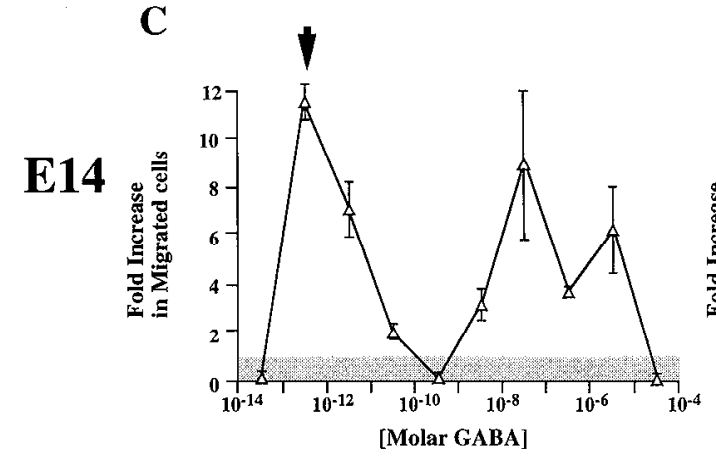

B

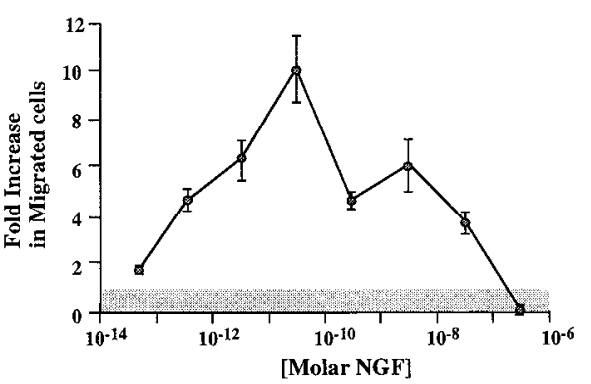

D

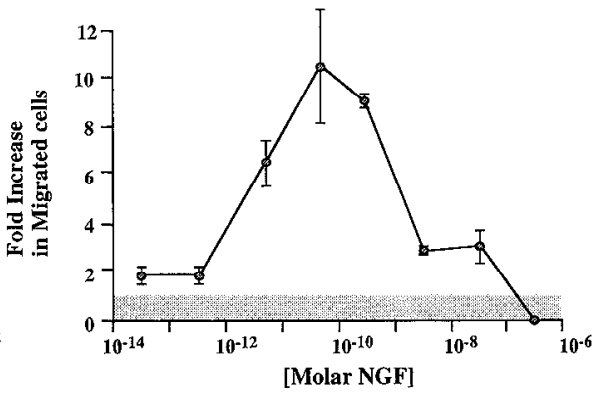

Figure 4. Dose responses of E13 and E14 cells to NGF and GABA. There were two peaks of migratory responses to GABA (triangles). At E13, nanomolar concentrations $(50 \mathrm{nM})$ induced the greatest number of cells to migrate. A small number of cells, however, responded to femtomolar GABA ( $500 \mathrm{fm})$ $(A)$. At $\mathrm{E} 14$, there was an increase in the number of cells responding to femtomolar GABA. At this age, femtomolar, nanomolar, and micromolar GABA induced similar numbers of cells to migrate (C). Arrows ( $A, C$ ) highlight migration to femtomolar concentrations. At both E13 and E14, NGF-induced migration (circles) peaked at picomolar concentrations. The optimal concentration of NGF for inducing cell motility was $3.8 \times 10^{1 "} \mathrm{M}$, or $1 \mathrm{ng} / \mathrm{nnl}$ $(B, D)$. A small number of E13 cells migrated to nanomolar NGF $(B)$. Suboptimal and supraoptimal chemoattractant concentrations failed to evoke motility. The shaded areas indicate the spontaneous migration to buffer alone. for NF expression following fixation and cresyl violet staining. After the incubation in cresyl violet, migrated cells were rinsed in PBS and were then incubated $2 \mathrm{hr}$ at room temperature in anti-NF (tissue culture supernatant, 1:8 in PBS with $0.1 \%$ Triton $X-100$ ). The cells were washed three times and incubated in peroxidase-conjugated goat anti-mouse IgM (1:40; Jackson Immunoresearch, West Grove, PA) for $1 \mathrm{hr}$ at room temperature. Immunoreaction product was visualized using a diaminobenzidine substrate. Cresyl violet staining enabled the visualization of total cells, while the neurofilament staining appeared as a brown immunoreaction product that accumulated in the soma and neurites. Cells were counted under bright field using $25 \times$ Planapo objectives.

Immunofluorescent staining of tissue sections. Tissue sections were stained for GABA and NGF by double-label indirect immunofluorescence in order to localize these molecules in the developing spinal cord. E13 embryos were delivered by cesarean section and immersed in $4 \%$ $\mathrm{PF}$ for $48 \mathrm{hr}$ at $21^{\circ} \mathrm{C}$. Embryos were washed in PBS and cords were dissected. Spinal cords were allowed to equilibrate in $20 \%$ sucrose at $4^{\circ} \mathrm{C}$, and were embedded in M-1 matrix (Lipshaw, Detroit, MI); $12 \mu \mathrm{m}$ frozen scrial cross sections wcre collccted onto gclatin-coated slides. Sections were air dried at room temperature prior to immunostaining.

Sections were incubated in $10 \mu \mathrm{l}$ of anti-NGF $(25 \mu \mathrm{g} / \mathrm{ml}$; Boehringer Mannheim, Indianapolis, IN) and anti-GABA (1:300; Eugene Tech. Inc., Allendale, NY) antisera at $4^{\circ} \mathrm{C}$ overnight and washed. Fluorochrome-conjugated second antibodies (rhodamine isothiocyanate-goat anti-mouse IgG and FITC-goat anti-guinea pig IgG, both at 1:40; Jackson Immunoresearch, West Grove, PA) were applied to the sections for $1 \mathrm{hr}$ at $21^{\circ} \mathrm{C}$. Sections were washed, overlayed with $70 \%$ glycerol in PBS, and coverslips were sealed with nail polish. The sections were examined using a Zeiss $25 \times$ or $40 \times$ Planapo objective. Adjacent sections were counterstained with $0.1 \%$ cresyl violet to confirm the anatomical structures that were immunolabeled.

Polymerase chain reaction (PCR). Total RNA was isolated from dissociated cells of wholc cord, as well as ventral and dorsal E13 and E14 spinal cords (15-25 million cells per isolation, prepared as above) using the RNAzol B method and reagent (Tel-Test, Inc., Friendswood, TX). Precipitated and dried RNA was taken up in RNase-free (DEPC-treated) $\mathrm{H}_{2} \mathrm{O}$ and adjusted to $500 \mathrm{ng} / \mu \mathrm{l}$.

Reverse transcription and polymerase chain reaction (RT-PCR) were performed using the GeneAmp RNA PCR kit (Perkin Elmer, Norwalk, CT) according to the recommended protocol; $200 \mathrm{ng}$ of total RNA was used for each reaction. Reverse transcription using the furnished oligodT primers was carried out for $15 \mathrm{~min}$ at $42^{\circ} \mathrm{C}$, preceded by a $10 \mathrm{~min}$ incubation at room temperature for primer annealing and followed by
$5 \mathrm{~min}$ at $95^{\circ} \mathrm{C}$ for dissociation and inactivation of reverse transcriptase. The PCR reaction mixture contained $2 \mathrm{mM} \mathrm{MgCl}_{2}$ and the other components at the prescribed concentrations. The thermal cycling protocol included a $2 \mathrm{~min}$ preincubation at $95^{\circ} \mathrm{C}$, followed by 35 cycles of $1 \mathrm{~min}$ at $95^{\circ} \mathrm{C}$ (dissociation), $30 \mathrm{sec}$ at $60^{\circ} \mathrm{C}$ (primer annealing), and $30 \mathrm{sec}$ at $72^{\circ} \mathrm{C}$ (extension) and completed by a $7 \mathrm{~min}$ incubation at $72^{\circ} \mathrm{C}$ to finish primer extension. PCR products were separated on polyacrylamide gels (Novex, San Diego, CA), using BioMarker low DNA size standards (Bio Ventures, Murfreesboro, TN) as a reference. Gels were stained for 30 min with $0.5 \mu \mathrm{g} / \mathrm{ml}$ ethidium bromide solution, illuminated on a UV light source, and documented with black and white Polaroid film.

The primers for $t r k$ and NGF message were designed using the oligo 4.0-s software (National Biosciences, Plymouth, MN). Primer design was optimized with regard to melting temperature $\left(\sim 70^{\circ} \mathrm{C}\right)$, primer dimer formation, internal hairpin loops, and false priming sites within the target and the related sequence for rat $t r k \mathrm{~B}$ RNA (Middlemas et al., 1991). The open reading frame of the rat trk proto-oncogene sequence (Meakin et al., 1992) was used for the primer generation. The $t r k$ forward primer is 22 bases long, starts at base 953 in the open reading frame, and has the following nucleotide sequence: 5 -TCTTC AACGG CTCTG TGCTC AA-3'. The trk reverse primer is 22 bases long, starts at base 1316 in the open reading frame, and has the following nucleotide sequence: 5'-AGGAG GGCAG AAAGG AAGAG GG-3'. The $t r k$ PCR product is 364 base pairs (bp) long. Primers for NGF are based on the sequence for the NGF $\beta$-sequence (Whittemore et al., 1988). The NGF forward primer is 18 bases long, starts at base 113 in the open reading frame, and has the following nucleotide sequence: 5'-CTAAA CTTCA GCATT CCC-3'. The NGF reverse primer is 18 bases long, starts at base 621 in the open reading frame, and has the following nucleotide sequence: 5'-AAAGG TGTGA GTCGT GGT-3'. The NGF PCR product is 509 bp long.

To verify the identity of PCR products, restriction digests were performed using the MscI and NcoI rcstriction endonucleases (New England Biolabs, Boston, MA). These enzymes cut at base numbers 161 and 210 of the $t r k$ and NGF PCR products, respectively. Five microliters of $t r k$ and NGF PCR products from RT-PCRs (RNA obtained from dissociated cells of the whole E1 3 rat spinal cord) were subjected to an additional 30 cycle PCR using the above parameters. The reamplified DNA was puritied using the Magic PCR Preps kit (Promega, Madison, WI) according to the manufacturers instructions. Eight microliters of each fragment were mixed with $1 \mu \mathrm{l}$ of $10 \times$ digestion buffer and $10 \mathrm{U}$ of restriction endonuclease solution, and then incubated for $1 \mathrm{hr}$ at $37^{\circ} \mathrm{C}$. 
A

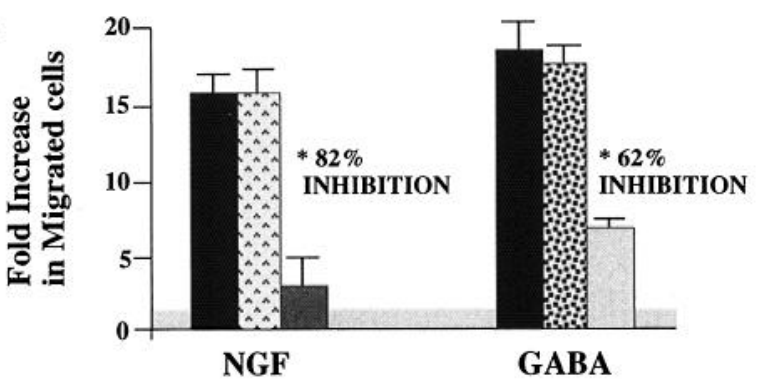

B

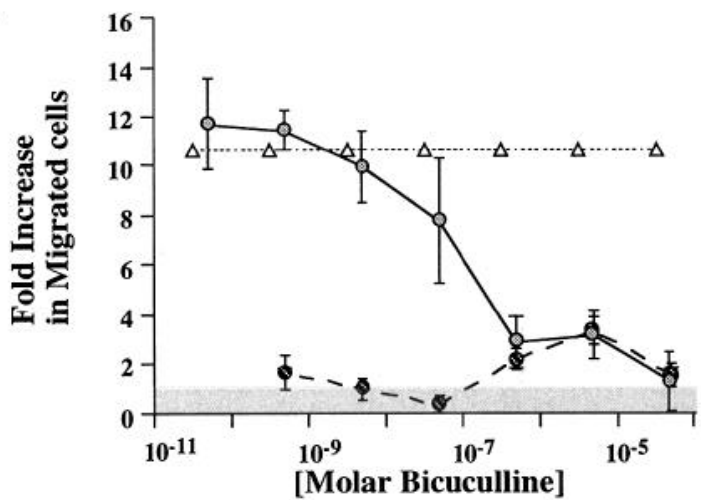

C

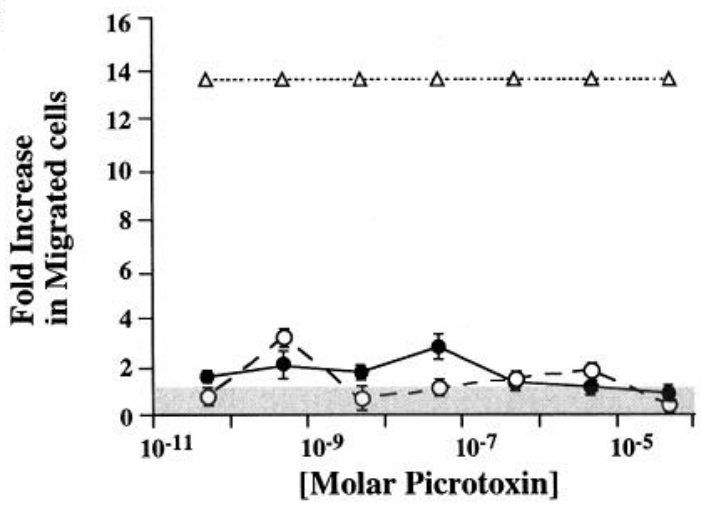

Figure 5. Inhibition of NGF-, GABA-, and muscimol-induced migration. $A$, Absorption of NGF and GABA with specific antibodies inhibited migration of E14 cells. Anti-NGF concentration was kept constant; the concentration of NGF was varied. NGF $(1 \mathrm{ng} / \mathrm{ml}$, or 3.8 $\times 10^{-11} \mathrm{M}$ ) preincubated with $25 \mu \mathrm{g} / \mathrm{ml}$ anti-NGF resulted in an $82 \%$ decrease in migrated cells. Excess NGF $\left(100 \mathrm{ng} / \mathrm{ml}\right.$, or $\left.3 \times 10^{-9} \mathrm{M}\right)$ preincubated with antibody did not inhibit migration. Solid bar, $1 \mathrm{ng} /$ $\mathrm{ml}$ untreated NGF; shaded bar, $1 \mathrm{ng} / \mathrm{ml}$ absorbed NGF; stippled bar, $100 \mathrm{ng} / \mathrm{ml}$ absorbed NGF. GABA concentration was kept constant; the concentration of anti-GABA was varied. GABA $\left(5 \times 10^{-8} \mathrm{M}\right)$ preincubated with anti-GABA antiserum (1:50) resulted in a $62 \%$ decrease in the number of migrated cells. GABA preincubated with more dilute antiserum (1:100) did not inhibit migration. Solid bar, untreated GABA; stippled bar, 1:100 anti-GABA; shaded bar, 1:50 anti-GABA. Antibodies alone did not induce migration. $B$ and $C, \mathrm{GABA}_{\mathrm{A}}$ antagonists inhibit muscimol-induced migration. Muscimol-induced migration $\left(5 \times 10^{-10}\right.$ м) of E14 cells was blocked by micromolar bicuculline and picomolar picrotoxin. Bicuculline and picrotoxin alone did not stimulate migration. The triangles indicate migration to muscimol only; the shaded area indicates spontaneous migration to buffer alone. In $B$, shaded circles represent bicuculline with muscimol; hatched circles represent bicuculline alone. In $C$, solid circles represent picrotoxin with muscimol; open circles represent picrotoxin alone.
Table 1. NGF-induced chemotaxis and GABA- and muscimolstimulated chemokinesis

\begin{tabular}{lll} 
& \multicolumn{2}{l}{ Location of chemoattractants } \\
\cline { 2 - 3 } $\begin{array}{l}\text { Chemo- } \\
\text { attractant }\end{array}$ & $\begin{array}{l}\text { Top and bottom wells } \\
\text { (chemokinesis) }\end{array}$ & $\begin{array}{l}\text { Bottom wells only } \\
\text { (chemotaxis) }\end{array}$ \\
\hline GABA & $12.03 \pm 1.17$ & $12.31 \pm 1.09$ \\
Muscimol & $33.11 \pm 2.83$ & $33.00 \pm 0.49$ \\
NGF & $0.20 \pm 0.09$ & $8.49 \pm 1.57$
\end{tabular}

Chemotaxis was distinguished from chemokinesis by placing the same concentration of chemoattractant in both the upper and lower wells of the chamber, thereby eliminating a chemical gradient. The number of cells migrating under these conditions was considered a measure of chemokinesis. Cells exhibited only chemotactic responses to NGF $(1 \mathrm{ng} / \mathrm{ml})$, and migrated only in the presence of a chemical gradient. Both GABA $\left(5 \times 10^{-8} \mathrm{M}\right)$ and muscimol $\left(5 \times 10^{-10} \mathrm{M}\right)$ stimulated chemokinetic responses in cells. The same number of cells migrated in the absence of a gradient as in the presence of one.

\section{Results}

\section{Cell migration}

The first chemotropic responses occur at E13. Maximum migratory responses occurred by $4 \mathrm{hr}$. Increasing the incubation time within chambers to $18 \mathrm{hr}$ did not result in a significant increase in the number of migrated cells. Cells derived from E12 spinal cords did not migrate in response to any concentration of the chemoattractants; the number of adhered cells on the underside of a membrane did not exceed the number of cells that spontaneously moved through pores in control wells. E13 was the earliest age at which a significant number of cells migrated in response to the chemoattractants.

NGF, GABA, and the $\mathrm{GABA}_{\mathrm{A}}$ agonist muscimol induced cell motility. At E13 and E14, cells migrated in response to all three chemoattractants. In contrast, only NGF induced motility in cells dissociated from E15 spinal cords. Peak migratory responses were detected at E13 and E14. By E15 the number of responding cells declined. At all ages, responses to GABA ranged 7-17-fold over the migratory levels of controls. Similarly, muscimol and NGF stimulated increased migration 7-17- and 833 -fold, respectively. Immunolabeling of the migrated cells revealed that all cells responding to NGF and $80 \%( \pm 6.00 \%)$ of the cells responding to GABA expressed NF, and hence were neurons (Fig. 3). Cells did not migrate to the amino acid control L-leucine.

Responses to chemoattractants are dose dependent. Migratory responses were dose dependent. Two discrete concentration ranges of GABA elicited cellular motility (Fig. 4A,B). At E13, nanomolar concentrations $(50-500 \mathrm{nM})$ induced the greatest number of cells to migrate; however, a small number of cells also migrated to femtomolar GABA $(500 \mathrm{fM})$. The number of cells responding to femtomolar levels of GABA increased at E14. At this age, low ( $500 \mathrm{fm}$ to $5 \mathrm{pM})$ and high ( $50 \mathrm{nM}$ to $5 \mu \mathrm{M})$ ranges of concentration stimulated similar numbers of cells to migrate (Fig. $4 C$ ). Dilutions of GABA between these ranges did not induce motility, and higher GABA levels $(50 \mu \mathrm{M})$ failed to elicit migration, indicating that at both E13 and E14, subpopulations of spinal cord cells only respond to two distinct GABA concentration ranges that are many orders of magnitude apart.

Cells derived from E13 and E14 cords showed similar migratory responses to NGF (Fig. $4 B, D)$. Picomolar NGF $(3.8 \times$ $10^{-11} \mathrm{M}$; or $1 \mathrm{ng} / \mathrm{ml}$ ) induced the greatest number of cells to migrate; however, at E13 a small but significant number of cells responded to nanomolar NGF (Fig. $4 B$ ). 
In order to confirm the specificity of the chemotropic effects, we preabsorbed NGF and GABA with specific antibodies prior to placing them in the bottom wells of the chamber. Preabsorption of GABA and NGF with specific antibodies blocked migration (Fig. $5 A$ ), demonstrating the specificity of the GABA and NGF motility signals.

Picomolar muscimol (500 pM), a $\mathrm{GABA}_{\mathrm{A}}$ receptor agonist (Sivilotti and Nistri, 1991), mimicked the effects of GABA, indicating migratory responses may be mediated through GA$\mathrm{BA}_{\mathrm{A}}$ receptor proteins. Therefore, we attempted to inhibit muscimol-induced migration using $\mathrm{GABA}_{\mathrm{A}}$ receptor antagonists (Sivilotti and Nistri, 1991). In competition assays, micromolar bicuculline completely blocked migratory responses to muscimol (Fig. $5 B$ ). Similarly, picrotoxin, also a $\mathrm{GABA}_{\mathrm{A}}$ antagonist, inhibited muscimol induced migration by $75 \%$ at all concentrations assayed (micromolar to picomolar) (Fig. 5C).

$N G F$ induces chemotaxis and GABA induces chemokinesis of embryonic neurons. NGF induced only chemotaxis while cellular responses to GABA were chemokinetic (Table 1). Cells only migrated toward NGF in the presence of a chemical gradient. In contrast, exposure of cells to appropriate GABA or muscimol concentrations, even in the absence of a gradient, resulted in significant migration.

\section{Identification of GABA, NGF, and trk in spinal cord}

$N G F$ and GABA colocalize in fibers located in the ventral region of the E13 spinal cord. Double-label immunofluorescent staining of E13 cervical spinal cord sections revealed that NGF and GABA are present in the ventral spinal cord, where they colocalize within fibers that surround the ventral commissure and ventral horns. NGF immunoreactivity was predominantly located in the fibers within the ventral regions; however, fibers within the neuroepithelium and the lumen edge of the central canal were also lightly stained (Fig. 6).

Cells within the ventral and dorsal regions express trk and $N G F m R N A$. Cells dissociated from E13 and E14 spinal cords were analyzed by PCR for expression of the trk proto-oncogene, which encodes the high-affinity NGF receptor (Kaplan et al., 1991a,b; Klein et al., 1991; Meakin et al., 1992), and the NGF $\beta$-subunit (encoding the active fragment of NGF) (Whittemore et al., 1988) (Fig. 7A). At both ages, $t r k$ and NGF mRNAs were detected in dissociated cells derived from whole cord, as well as in cells derived from ventral and dorsal cord regions.

To verify the identity of the amplified trk and NGF PCR products, they were digested with restriction endonucleases targeted to known internal sequences to produce a distinctive pattern of restriction products (see Materials and Methods). For both fragments, the generated restriction fragments appeared at their predicted positions (Fig. $7 B$ ).

\section{Discussion}

We have shown that picomolar concentrations of NGF and femtomolar and nanomolar concentrations of GABA stimulate embryonic spinal cord neurons to migrate in vitro. The chemotropic effects of GABA are mimicked by muscimol, and inhibited by bicuculline and picrotoxin, suggesting GABA-induced motility signals are mediated through GABA receptor proteins. The presence of GABA receptors in embryonic spinal cord neurons has been previously described (Mandler et al., 1990; Walton et al., 1993). We provide evidence that embryonic neurons isolated from tissue at early stages of development also express functional high-affinity NGF receptors, and that both
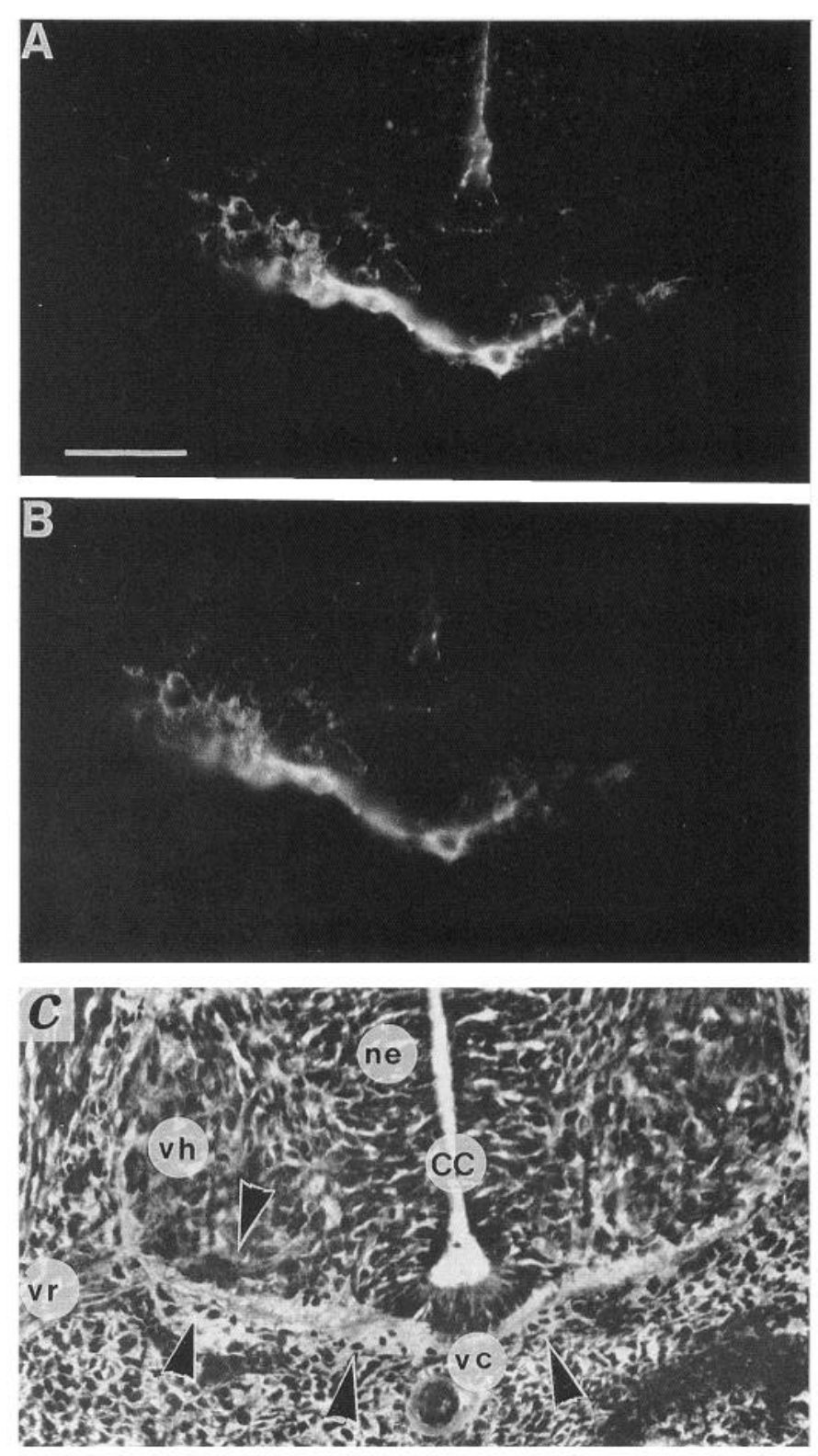

Figure 6. NGF and GABA are present in the ventral half of the cervical E13 spinal cord, where they colocalize in fibers. A, Photomicrograph of an E13 section stained by immunofluorescence for NGF demonstrates the presence of the factor in fibers comprising the ventral commissure and surrounding the ventral horns. $B$, The same section double labeled for GABA shows that the GABA colocalizes with NGF within the fibers. Immunoreactivity was predominantly located in fibers within the ventral regions. However, fibers within the neuroepithelium and the lumen edge of the central canal were also lightly stained. $C$, An adjacent section stained with cresyl violet illustrates the anatomic location of ventral horns $(v h)$, ventral commissure $(v c)$, ventral root $(v r)$, central canal $(c c)$, and neuroepithelium (ne); arrowheads indicate location of immunoreactive fibers. Scale bar, $120 \mu \mathrm{m}$.

NGF and GABA receptors appear to mediate chemotropic responses in these cells. Within the ventral half of the cord, NGF and GABA colocalize in anatomical regions near the target destinations of migratory neurons, suggesting these molecules provide relevant positional cues that direct neuroblast movement in vivo.

An in vitro chemotaxis assay was used to quantitate and characterize the chemotropic responses of embryonic spinal cord 

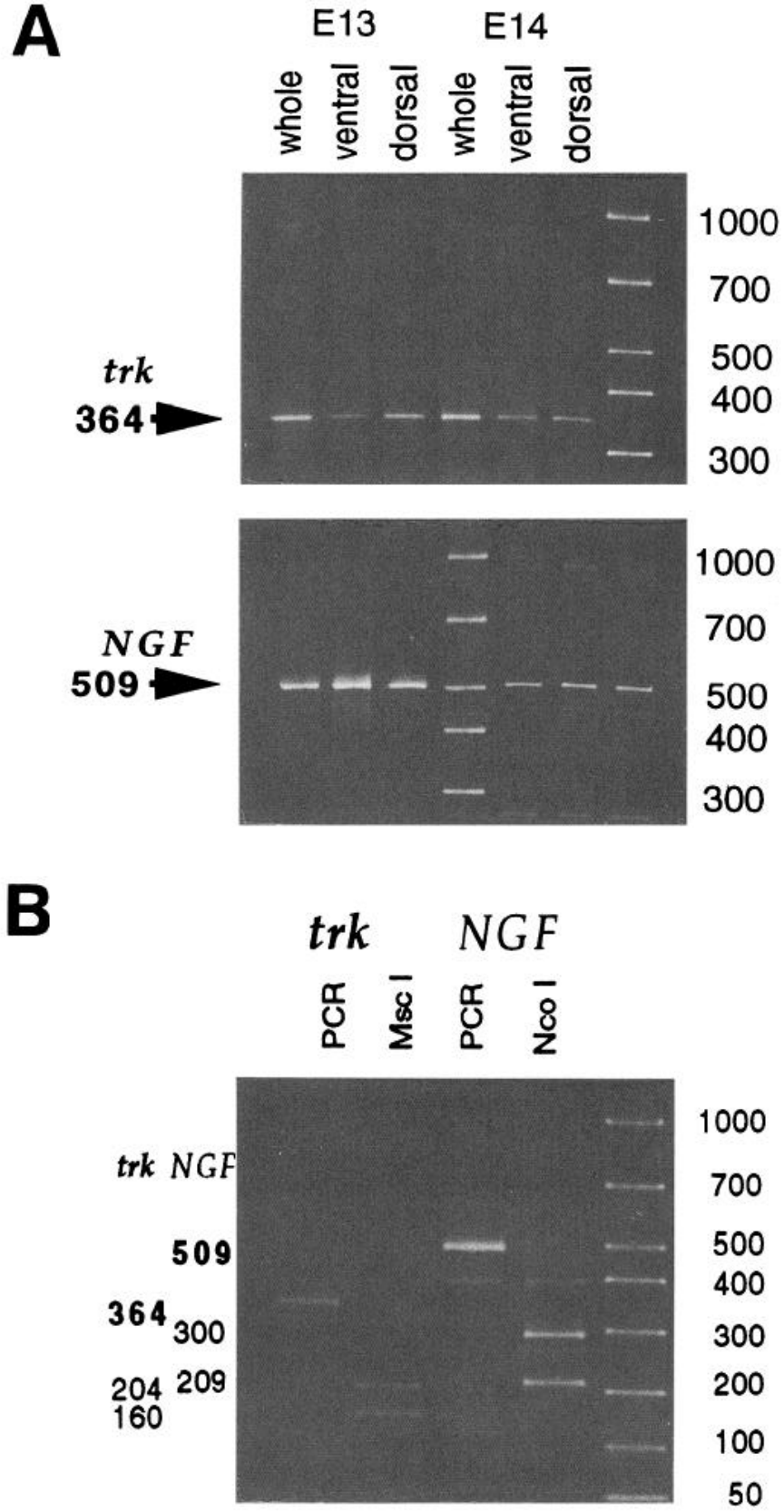

1000
500 400 300 200

Figure 7. PCR analysis of $t r k$ (high-affinity NGF receptor) and NGF mRNA. A, Identification of $t r k$ and NGF mRNA. PCR using $t r k$ (upper panel) and NGF (lower panel) primers was performed with RNA isolated from dissociated cells of whole, ventral, and dorsal E13 and E14 spinal cords (respectively, lanes $1-3$ and 4-6). Relative to the MW standards, the amplified DNA appears at the positions corresponding to the predicted base pair lengths of 364 for trk (upper panel) and 509 for NGF (lower panel). The PCRs for trk and NGF were performed with $1 \mu \mathrm{g}$ and $200 \mathrm{ng}$ of total RNA per reaction, respectively. Samples were run on $8 \%$ polyacrylamide gels. $B$, Verification of identity of $t r k$ and NGF PCR products. The PCR products for $t r k$ and NGF were digested with the MscI and NcoI restriction endonucleases as detailed in Materials and Methods. The restriction fragments appear at the predicted sizes of 160 and 204 for trk (lane 2) and 209 and 300 for NGF (lane 4), as shown next to their respective precursors (lanes 1 and 3 ). Samples were run on $8-16 \%$ polyacrylamide gradient gels.

neurons to NGF and GABA. This assay was designed to present cell receptors with an environmental discontinuity of chemoattractant, thus mimicking the diffusible gradient of molecules that cells might encounter in vivo. Chemotaxis is thought to be mediated by an uneven distribution, or polarity of ligand binding along one axis of a cell (Caterina and Devreotes, 1991). Receptors on one side of the cell bind ligand, while those on the opposite side do not. This disparity in binding initiates a polarity of intracellular signals (Brundage et al., 1991), which results in directed migration toward increasing concentrations of ligand. Thus, cells "sense" the chemical gradient and move toward the source of the chemoattractant. In the chemotaxis chamber, cells settle onto the filter and fill the pores. Only receptors on the underside of a cell situated within a pore of the filter are exposed to chemoattractants in the lower compartment of the chamber. The remaining receptors are exposed to buffer in the upper wells. The cell experiences a polarity of ligand binding that mimics the environment of a chemical gradient a cell might encounter in vivo.

If chemotaxis is involved in CNS development, chemoattractants should be released in target locations or along migratory pathways. Both GABA and NGF fit these criteria. By E13, motoneurons, the first neurons to differentiate within the cord (Nornes and Das, 1974), have begun to migrate out of the neuroepithelium toward the ventral horns, where GABA- and NGFcontaining fibers are present. Detection of NGF mRNA in E13 and E14 dissociated cord cells suggests that the immunoreactive fibers originate from spinal cord neurons that extend processes into the ventral horns and commissure. Within ventral horn regions, NGF and GABA may act as chemoattractants to guide embryonic motoneuronal migration. Release of NGF and GABA from fibers could result in diffusible gradients of molecules localized in the ventral horns. Evidence for release of both molecules by embryonic cells has been reported. During synaptogenesis, NGF is released from target tissues destined to be innervated by sympathetic and sensory axons (Levi-Montalcini, 1987), and GABA is released from the growth cones of developing axons of cultured cells (Gordon-Weeks et al., 1984; Taylor et al., 1990). Release of these molecules from descussating or descending fibers in the E13 spinal cord may provide postmitotic neuroblasts within the neuroepithelium with a source of chemotropic signals.

In order to respond to chemotropic signals, cells must express receptors for the molecules at the appropriate stage of development. By E13, spinal cord cells show depolarizing GABA responses that are blocked by bicuculline and picrotoxin (Mandler et al., 1990; Walton et al., 1993). In the present study, GABA and the $\mathrm{GABA}_{\mathrm{A}}$ receptor agonist muscimol stimulated embryonic neurons to migrate. Bicuculline and picrotoxin, GA$\mathrm{BA}_{\mathrm{A}}$ receptor antagonists, inhibited muscimol-induced migration, indicating in vitro chemotropic responses to GABA may be mediated through $\mathrm{GABA}_{\mathrm{A}}$ receptor $\mathrm{Cl}^{-}$channels. In vivo, these receptors may mediate motility signals in embryonic, migratory spinal cord neurons.

Classically described $\mathrm{GABA}_{\mathrm{A}}$ receptors form $\mathrm{Cl}^{-}$channels in mature neurons; cells are polarized following binding of GABA or muscimol, according to the existing $\mathrm{Cl}^{-}$gradient. In postnatal and adult mammalian CNS, GABA hyperpolarizes cells (Sivilotti and Nistri, 1991). Early embryonic responses to GABA, however, are excitatory; subpopulations of cells depolarize in response to GABA and muscimol (Fiszman et al., 1990; Mandler et al., 1990; Walton et al., 1993). Neuroblasts that depo- 
larize in response to GABA may have receptor proteins coupled to alternative signal transduction mechanisms that mediate motility. Although the pharmacology of the GABA-induced migratory response suggests the involvement of $\mathrm{GABA}_{\mathrm{A}}$ receptorcoupled $\mathrm{Cl}^{-}$channels, further experiments are needed to elucidate the cellular and molecular mechanisms.

E13 spinal cord cells express low-affinity NGF receptors (Yan and Johnson, 1988). All biological responses to NGF, however, are thought to be mediated through high-affinity NGF receptors (Sutter et al., 1979; Bernd and Greene, 1984; Greene et al., 1986). PCR analysis of cells isolated from E13 and E14 spinal cord demonstrates the presence of trk mRNA, suggesting these cells contain message encoding the high-affinity receptor (Kaplan et al., 1991a; Klein et al., 1991). In the chemotaxis assay, the optimal concentration of NGF for induction of cellular motility was $3.8 \times 10^{-11} \mathbf{M}$, or $1 \mathrm{ng} / \mathrm{ml}$. This concentration directly corresponds to the $K_{D}$ value for equilibrium binding of NGF to high-affinity NGF receptors (Stach and Perez-Polo, 1987). Preabsorption of NGF blocked neuroblast migration. Together, these results suggest that early embryonic spinal cord cells express functional, high-affinity NGF receptors, and that specific NGF binding to these receptors mediates motility. The cellular and molecular mechanisms transducing NGF motility signals remain to be resolved.

Dose-response studies demonstrate that distinct ranges of concentrations stimulate cells to migrate. Suboptimal and supraoptimal concentrations do not evoke motility. These results may reflect receptor-mediated mechanisms operable in vivo. Just as low concentrations may fail to stimulate cells to move, excess levels of chemoattractants may also inhibit migration. As cells move along a chemical gradicnt in vivo, they encounter high levels of the chemoattractant as they approach their target destination. High concentrations may desensitize or overstimulate cells, triggering mechanisms that inhibit further migration (Caterina and Devreotes, 1991; Tessier-Lavigne and Placzek, 1991).

In this study, two discrete concentration ranges of GABA induced cellular motility. Dilutions of GABA separating these two ranges did not evoke a migratory response, indicating subpopulations of spinal cord cells only respond to distinct GABA concentration ranges that are many orders of magnitude apart. These results could mean that the migrating cells represent at least two subpopulations equipped with low- and high-affinity GABA receptors. Alternatively, one subpopulation may have more receptors than the other. Analysis of GABA receptor density as well as receptor-subunit expression of the migratory cells could resolve differences between the two populations.

NGF and GABA appear to convey different chemotropic signals. NGF only stimulates chemotaxis, while cellular responses to GABA are chemokinetic. Within the developing spinal cord, the combined motility signals of NGF and GABA may coordinate neuronal migration. Chemokinetic responses to GABA may initiate motility in postmitotic neuroblasts, while diffusible gradients of NGF provide chemotactic cues that guide cells toward their target locations.

Several studies suggest that NGF and GABA serve as trophic factors in the developing CNS (Gordon-Weeks et al., 1984; Hanson et al., 1984; Levi-Montalcini, 1987; Taylor et al., 1990; Lauder, in press). Recent reports suggest that other neurotransmitters may act as chemoattractants during development (Lauder, 1993). In cerebellar slice preparations, $N$-type calcium channel antagonists were observed to inhibit granule cell mi- gration (Komuro and Rakic, 1992). Observation of the effects of GABA and NGF antagonists on migrating neurons within embryonic spinal cord slices would provide direct evidence that these molecules influence cell movement in more intact preparations.

NGF and GABA colocalize in tibers that emerge early during neurogenesis not only in the spinal cord but also other areas of the CNS (Lauder ct al., 1986), and cells in many regions transiently express GABA, NGF, or their receptors during development (Marchetti and McManaman, 1990; Messersmith and Redburn, 1992; Ma et al., 1993; Lauder, 1993). These results suggest that NGF and GABA may influence the migration of subpopulations of neuroblasts in several regions of the developing CNS.

In summary, we have used an in vitro chemotaxis assay to quantitate and characterize the migratory responses of neurons to various molecules. This method is a sensitive measure of cellular responses to specific chemotropic signals. We have shown that embryonic neurons acutely isolated from the developing spinal cord are stimulated to migrate in vitro by discrete concentration ranges of NGF or GABA, which appear to act as specific signaling molecules. The fact that NGF and GABA are present in the developing spinal cord, and that embryonic neurons express functional receptors for these molecules during developmental stages in which migration occurs, suggests that these two molecules may have relevant roles as chemoattractants, and that chemotactic and chemokinetic responses of neuroblasts to NGF and GABA are important in determining the ultimate position of neurons in the CNS.

\section{References}

Armstrong RC, Harvath L, Dubois-Dalcq M (1990) Type I astrocytes and oligodendrocyte-type 2 astrocyte glial progenitors migrate toward distinct molecules. J Neurosci Res 27:400-407.

Behar T, Schaffner A, Laing P, Hudson L, Komoly S, Barker J (1993) Many spinal cord cells transiently express low molecular weight forms of glutamic acid decarboxylase during embryonic development. Dev Brain Res 72:203-218.

Bernd P, Greene LA (1984) Association of [ $\left.{ }^{125} \mathrm{I}\right]$-nerve growth factor with PC12 pheochromocytoma cells. J Biol Chem 259:15509-15516.

Brundage RA, Fogarty KF, Tuft RA, Fay FS (1991) Calcium gradients underlying polarization and chemotaxis of eosinophils. Science 254 : 703-706

Caterina MJ, Devreotes PN (1991) Molccular insights into cukaryotic chemotaxis. FASEB J 5:3078-3085.

Eisen JS (1991) Determination of primary motoneuron identity in developing zebrafish embryos. Science 252:569-572.

Falk W, Goodwin RH, Leonard EJ (1980) A 48 well micro chemotaxis assembly for rapid and accurate measurement of leukocyte migration J Immunol Methods 33:239-247.

Fishell G, Mason CA, Hatten ME (1992) Lateral dispersion of premigratory, neuronal progenitors within the ventricular zone of cerebral cortex. Soc Neurosci Abstr 18:926.

Fiszman ML, Novotny EA, Lange GD, Barker JL (1990) Embryonic and early postnatal hippocampal cells respond to nanomolar concentrations of muscimol. Dev Brain Res 53:186-193.

Gordon-Weeks PR, Lockerbie RO, Pearce B (1984) Uptake and release of ${ }^{3}[\mathrm{H}] \mathrm{GABA}$ by growth cones isolated from neonatal rat forebrain. Neurosci Lett 52:205-210.

Greene LA, Aletta JM, Ruckenstein A, Green SH (1986) PC12 pheochromocytoma cells: culture, nerve growth factor treatment, and experimental exploitation. Methods Enzymol 147:207-216.

Hanson PG, Meier E, Schousboe A (1984) GABA influences the ultrastructural composition of cerebellar granule cells during development in culture. Int J Dev Neurosci 2:247-257.

Harvath L, Falk W, Leornard EJ (1980) Rapid quantitation of neutrophil chemotaxis: use of a polyvinylpyrrolidone-free polycarbonate membrane in a multiwell assembly. J Immunol Methods 37:39-45. 
Hatten ME (1990) Riding the glial monorail: a common mechanism for glial-guided migration in different regions of the developing brain. Trends Neurosci 13:179-184.

Hirano S, Fuse S, Sohal GS (1991) The effect of the floor plate on pattern and polarity in the developing central nervous system. Science 251:310-313.

Kaplan DR, Hempstead BL, Martin-Zanca D, Chao MV, Parada LF (1991a) The $t r k$ proto-oncogene product: a signal transducing receptor for nerve growth factor. Science 252:554-560.

Kaplan DR, Martin-Zanca D, Parada LF (1991b) Tyrosine phosphorylation and tyrosine kinase activity of the trk proto-oncogene product induced by NGF. Nature 350:158-160.

Klein R, Jing S, O'Rourke E, Barbacid M (1991) The trk-protooncogene encodes a receptor for nerve growth factor. Cell 65:189-197.

Kumuro H, Rakic, P (1992) Selective role of N-type calcium channels in neuronal migration. Science 257:806-809.

Lauder JF (1993) Neurotransmitters as growth regulatory signals: role of receptors and second messengers. Trends Neurosci 16:233-240.

Lauder JM, Han VKM, Henderson P, Verdoorn T, Towle AC (1986) Prenatal ontogeny of the GABAergic system in the rat brain: an immunocytochemical study. Neuroscience 19:465-493.

Levi-Montalcini R (1987) The nerve growth factor: thirty-five years later. EMBO J 6:1145-1154.

Ma W, Behar T, Barker J (1992) Transient expression of GABA immunoreactivity in the developing rat spinal cord. J Comp Neurol 325: 271-290.

Mandler RN, Schaffner AE, Novotny EA, Lange GD, Smith SV, Barker JL (1990) Electrical and chemical excitability appear one week before birth in the embryonic rat spinal cord. Brain Res 522:46-54.

Marchetti D, McManaman JL (1990) Characterization of nerve growth factor binding to embryonic rat spinal cord neurons. J Neurosci Res 27:211-218.

Markham JA, Vaughn JE (1991) Migration patterns of sympathetic preganglionic neurons in embryonic rat spinal cord. J Neurobiol 22 : $811-822$.

Meakin SO, Suter U, Drinkwater CC, Welcher AA, Shooter EM (1992) The rat $t r k$ proto-oncogene product exhibits properties characteristic of the slow nerve growth factor receptor. Proc Natl Acad Sci USA 89:2374-2378.

Messersmith EK, Redburn DA (1992) $\gamma$-Aminobutyric acid immunoreactivity in multiple cell types of the developing rabbit retina. Vis Neurosci 8:201-211.

Middlemas DS, Lindberg RA, Hunter T (1991) trkB, a neural receptor protein-tyrosine kinase: evidence for a full-length and two truncated receptors. Mol Cell Biol 11:143-153.

Nornes HO, Das GD (1974) Temporal pattern of neurogenesis in spinal cord of rat. I. An autoradiographic study-time and sites of origin and migration and settling patterns of neuroblasts. Brain Res $73: 121-138$.

O'Rourke NA, Dailey ME, Smith SJ, McConnell SK (1992) Diverse migratory pathways in the developing cerebral cortex. Science 258 : 299-302.

Rakic P (1972) Mode of cell migration of the superficial layers of fetal monkey neocortex. J Comp Neurol 145:61-84.

Rakic P (1990) Principles of neural cell migration. Experientia 46: 882-891.

Schaffner A, Behar T, Nadi S, Barker JL (1993) Quantitative analysis of transient GABA expression in embryonic and early postnatal rat spinal cord neurons. Dev Brain Res 72:265-276.

Sivilotti L, Nistri A (1991) GABA receptor mechanisms in the central nervous system. Prog Neurobiol 36:35-92.

Stach RW, Perez-Polo JR (1987) Binding of nerve growth factor to its receptors. J Neurosci Res 17:1-10.

Sutter A, Riopelle RJ, Harris-Warrick RM, Shooter EM (1979) Nerve growth factor receptors. Characterization of two distinct classes of binding sites on chick embryo sensory ganglia cells. J Biol Chem 254: 5972-5980.

Taylor J, Docherty M, Gordon-Weeks PR (1990) GABAergic growth concs: rclcase of endogenous $\gamma$-aminobutyric acid precedes the expression of synaptic vesicle antigens. J Neurochem 54:1689-1700.

Tessier-Lavigne M, Placzek M (1991) Target attraction: are developing axons guided by chemotropism? Trends Neurosci 14:303-310.

Walsh C, Cepko CL (1992) Widespread dispersion of neuronal clones across functional regions of the cerebral cortex. Science 255:373.

Walton MK, Schaffner AE, Barker JL (1993) Sodium channels, GA$\mathrm{BA}_{\mathrm{A}}$ receptors, and glutamate receptors develop sequentially on embryonic rat spinal cord cells. J Neurosci 13:2068-2084.

Whittemore SR, Friedman PL, Larhammar D, Persson H, GonzalezCarvajal M, Holets VR (1988) Rat beta-nerve growth factor sequence and site of synthesis in the adult hippocampus. $\mathbf{J}$ Neurosci Res 20:403-410.

Yan Q, Johnson EM Jr (1988) An immunohistochemical study of the ncrve growth factor receptor in developing rats. J Neurosci 8:34813498.

Yao J, Gilbert D, Colton C (1990) Chemotaxis of cultured CNS microglia. J Neurosci Res 27:36-42. 